\title{
ATRIBUTOS FíSICOS, QUÍMICOS E BIOLÓGICOS RELACIONADOS COM A ESTABILIDADE DE AGREGADOS DE DOIS LATOSSOLOS EM PLANTIO DIRETO NO ESTADO DE SÃO PAULO ${ }^{(1)}$
}

\author{
G. DUFRANC(2), S. C. F. DECHEN ${ }^{(3)}$, \\ S. S. FREITAS ${ }^{(3)} \&$ O. A. CAMARGO(4)
}

\begin{abstract}
RESUMO
Com o objetivo de verificar a influência de atributos físicos, químicos e biológicos na estabilidade de agregados em água de dois L atossolos sob plantio direto há mais de quatro anos, foi amostrada a camada de 0-10 cm de duas áreas, utilizando uma grade de amostragem de $100 \mathrm{~m}$ entre pontos, georreferenciados com DGPS. Uma das áreas está localizada no município de Campos Novos Paulista, SP (22 • $36^{\prime} 11$ " latitude e 50 00 ' 09 " longitude) em um Latossolo Vermelho distrófico típico álico textura média A moderado (LVd-CNP), e a outra se localiza no município de Angatuba, SP (23 29 ' 23 "latitude e 48 ० 24 ' 46 " longitude), em Latossolo Vermelho distrófico típico álico textura argilosa A moderado (LVd-Anga). Os valores do diâmetro médio ponderado (DMP) e dos atributos físicos, químicos e biológicos foram analisados mediante regressões lineares múltiplas, em pré-tratamentos com água, álcool e benzeno. Os resultados mostraram que a matéria orgânica, a comunidade bacteriana e os teores de Fe, de $\mathrm{K}$ e de argila foram os principais agentes agregantes. Em áreas com baixos teores de argila e altos teores de areia fina, baixos índices de estabilidade foram encontrados. Mesmo estando sob plantio direto há mais de quatro anos, o LVdCNP mostrou índices de estabilidade de agregados muito baixos, graças, principalmente, ao seu alto conteúdo de areia fina. E m relação ao LVd-CNP, o LVd-Anga apresentou índices de agregação mais elevados, principalmente por causa do alto teor de argila e maior quantidade de matéria orgânica.
\end{abstract}

Termos de indexação: sistemas de preparo do solo, física do solo, fertilidade do solo, microbiota do solo, pré-tratamento.

(1) Parte da Tese de Mestrado do primeiro autor, apresentada na III I nternational Conference on Land Degradation and Meeting of the International Union of Soil Sciences - Subcommission C, Rio deJ aneiro (RJ ), de 17 a 21 de setembro de 2001 . Recebido para publicação em dezembro de 2001 e aprovado em maio de 2004.

(2) Engenheiro-Agrônomo, Mestre em Agricultura Tropical e Subtropical, Instituto Agronômico - IAC. Caixa Postal 28. CEP 13020902 Campinas (SP). Bolsista FAPESP. E-mail: guidodufran@yahoo.com.br

(3) Pesquisadora Científica do Centro de Pesquisa e Desenvolvimento de Solos e Recursos Ambientais, IAC. E-mail: dechen@iac.sp.gov.br; sfreitas@iac.sp.gov.br

(4) Pesquisador Científico do Centro de Pesquisa e Desenvolvimento de Solos e Recursos Ambientais, IAC. Bolsista CNPq. E-mail: ocamargo@iac.sp.gov.br 


\title{
SUMMARY: PHYSICAL, CHEMICAL AND BIOLOGICAL SOIL ATTRIBUTES RELATED TO AGGREGATE STABILITY OF TWO OXISOLS UNDER NO-TILLAGE IN THE STATE OF SÃO PAULO, BRAZIL
}

\begin{abstract}
The effect of physical, chemical and biological soil attributes on the stability of wet aggregates of two Oxisols cultivated with annual crops under no till age for over four years was evaluated. Soils samples were collected in the 0-10 cm layer of two areas in a $100 \mathrm{~m}$ square grid marked with a DGPS. One of the areas is located in Campos Novos Paulista county, SP, Brazil (22 $236^{\prime} 11$ " latitudeand $50^{\circ} 00^{\prime} 09^{\prime \prime}$ "longitude) on a sandy loam Oxisol. The other area is in Angatuba county, SP, Brazil (23 $29^{\prime}$ ' $23^{\prime \prime}$ latitude and $48^{\circ} 24^{\prime} 46$ " longitude) on a clayey Oxisol. Multiple linear regression analysis was carried out for the mean weighted diameter (MWD) results and soil attri butes according to the pretreatments methods (water, alcohol and benzene) and aggregation agents. Theresults showed that the organic matter content, bacterial community, iron, potassium, and clay content were the most important parameters for soil aggregation. In areas with low clay and high finesand content it was found low stability indexes. Even though the sandy loam Oxisol has been under no-tillagefor over four years, it presented low stability indexes, mainly because of the low clay and high fine sand content. The clayey Oxisol showed higher aggregate stability compared to the sandy loam Oxisol, mainly because of its higher clay and organic matter content.
\end{abstract}

Index terms: soil tillage systems, soil physics, soil fertility, soil biology, pre-treatment.

\section{INTRODUÇÃO}

Agregados do solo podem ser definidos como "uma união natural ou grupo de partículas nas quais as forças que mantêm os colói des juntos são muito mais fortes que entre agregados adjacentes" (Martin et al., 1955). O estado de agregação do solo é de grande importância para as atividades agrícolas, uma vez que está relacionado com a aeração do solo, desenvolvimentoradicular, suprimento denutrientes, resistência mecânica do solo à penetração, retenção e armazenamento de água (K ohnke, 1968). Solos de boa estabilidade estrutural estão menos sujeitos à compactação e à erosão (Russel, 1973). Os atributos do solo que determinam a estabilidade estrutural estão ligados à textura, à mineralogia das argilas, à matéria orgânica, ao material inorgânico não-cristalino, à composição de fluidos do meio poroso, às plantas e organismos do solo e à profundidade do perfil do solo (Kay \& Angers, 1999).

A matéria orgânica age como condicionador do solo mediante sua estrutura complexa e longas cadeias de carbono, agregando partículas minerais. Além das estruturas complexas, a maior parte da matéria orgânica do solo é pouco mol hável, protegendo os agregados contra o umedecimento e quebra (Hénin et al., 1976). Sabe-se que a maior parte da fração orgânica no sol o é estável e chamada defração húmica (Fassbender, 1980), que irá formar agregados estáveis e persistentes no solo (Tisdal \& Oades, 1982).
A importância das frações orgânicas na agregação do sol o tem sido amplamente comprovada por meio de correlações entre as frações e os índices de agregação, pelo efeito do pré-tratamento com periodato, do qual resulta a oxidação de polímeros e diminuição da estabilidade de agregados, e por mudanças na estabilidade de agregados em rel ação à fração extraível de carbono em solos incubados (Degens, 1997). Muitos autores citama importância de sistemas de manejo do sol o que visam ao menor tráfego de máquinas, menor revolvimento do solo e aumento do teor de carbono orgânico (CO), como o plantio direto e o pousio, como medidas para recuperar as propriedades físicas do solo (Campos et al., 1995; Castro Filho et al., 1998; Silva \& Mielniczuk, 1997).

Bactérias e fungos são capazes de unir a fração mineral do solo em agregados estáveis, porém cada microrganismo tem uma eficiência específica quando se trata de agregar partículas (Harris et al., 1966). Guggenberger et al. (1999) verificaram que o crescimento da comunidade fúngica proporcionado pela adição de fontes de energia levou à aproximação de partículas primárias por enlaces de hifas que formaram agregados. Dados semelhantes foram encontrados por Molope et al. (1987), que também verificaram que, quando a comunidade bacteriana cresce, há decréscimo da comunidade fúngica. Degens et al. (1994) observaram que a presença de hifas num solo arenoso não foi suficiente para promover estabilização significativa de agregados. A importância dos microrganismos está relacionada 
com o efeito adesivo de polissacarídeos extracelulares provindos de hifas e de bactérias, que diminuem a destruição de agregados por aumentar sua resistência ao umedecimento (Guggenberger et al., 1999), ou de "colas" provenientes de resíduos orgânicos adsorvidos à fração argila (Hart et al., 1988, citados por Degens et al., 1994).

Das três classes de partículas primárias do solo, a argila é o fator mais importante para a estabilidade de agregados (Russel, 1973). A fração argila exerce domínio sobre o comportamento do solo em virtude de sua pequena dimensão, o que aumenta de maneira significativa sua superfície específica, e da presença de cargas negativas permanentes. Mbagwu et al. (1993) verificaram que solos com grandes quantidades deareia fina esilte dispersamse facilmente e que solos com boa estabilidade de agregados estão relacionados com a soma dos teores de argila e areia grossa, bem como a estabilidade de agregados tem relação com o teor de argila e areia grossa. Assim, supõe-se que partículas de areia grossa tenham microlocais favoráveis à deposição, principalmente, de polissacarídeos que se unem aos minerais de argila por pontes de cátions com el evado poder de absorção de água e diminuição de seu potencial energético. Dentre esses cátions está, por exemplo, o Fe. Pode ser que a areia grossa, em seu perímetro, tenha grande número de arestas com altas concentrações de cargas e possibilidade de adsorver cátions, minerais de argila e materiais orgânicos, agregando partículas.

J á Boix-Fayos et al. (2001) observaram que apenas a fração argila se correlacionava positivamente com os índices de agregação do solo. Segundo Dutartre et al . (1993), a fração areia somente formou agregados, quando suas partículas estavam "cimentadas" por microagregados de origem orgânica ou mineral.

A importância da argila e da matéria orgânica na estabilização dos agregados freqüentemente sobrepõe-se à dos cátions. De acordo com o modelo proposto por Edwards \& Bremer (1967), cátions pol ival entes são cruciais para unir a fração orgânica e os minerais de argila. Sem essa união, as frações argila e orgânica dispersam-se, pois ambas têm cargas negativas permanentes. Os cátions trocáveis do solo influenciam o processo de agregação, de acordo com a série liotrópica da química coloidal (Arena, 1968).

Quando uma partícula seca deargila éumedecida com água, há interação entre as moléculas de água e a superfície das argilas. Algumas moléculas de água são adsorvidas pela superfície das argilas por pontes de hidrogênio e outras moléculas deágua são adsorvidas por íons. Assim ocorre a hidratação de íons, que resulta, em alguns casos, na dissociação de íons e argilas. Os cátions têm maior capacidade de adsorção de água - e, conseqüentemente, maior resistência à dispersão - de acordo com seu número de cargas etamanho. Quanto mais cargas, menor o tamanho do cátion, ou seja, quanto maior a densidade de cargas, maior a resistência à dispersão (Russel, 1973). A resistência à dispersão também é influenciada pel o diâmetro do cátion hidratado, isto é, quanto menor o diâmetro, menor a probabilidade de dispersão, porque cátions hidratados de menor diâmetro são adsorvidos com maior força pela superfície das argilas (Rengasamy et al., 1986).

Dos quatro cátions encontrados em maior quantidade no solo ( $\mathrm{Ca}, \mathrm{Mg}, \mathrm{K}, \mathrm{Na}$ ), o efeito do $\mathrm{K}$ trocável nas propriedades físicas e hidráulicas é talvez o menos esclarecido, diante das divergências de resultados de pesquisa (Levy \& Torrento, 1995). Camargo et al. (1983) verificaram que o aumento da saturação por $\mathrm{K}$ no solo, aliado ao teor de CO, aumentou a estabilidade dos agregados. Ceconi et al. (1963) e Ravina (1973), citados por Levy \& Torrento (1995), constataram que solos saturados por $\mathrm{K}$ tinham mais agregados estáveis, quando comparados a solos saturados por Ca.

No entanto, Russel (1973) mediu a quantidade de calor liberada no processo de umedecimento de argila e verificou que solos saturados por $\mathrm{Ca}$ liberavam em torno de 200] /100 g para cada milimol de Ca trocável e, naquel es saturados por $K$, apenas 60J /100 g para cada milimol deK. Levy \& Torrento (1995) verificaram que o K, nas concentrações de $1,5 \%$ a aproximadamente $10 \%$, agiu como dispersante; porém, em concentrações maiores (10 a $15 \%$ ), tal efeito não foi verificado. Cruvinel et al. (1993) encontraram maior concentração de Ca em agregados menores e maior concentração de $\mathrm{K}$ em agregados maiores. A maior quantidade de $\mathrm{Ca}$ encontrado nos agregados menores foi atribuída à maior superfície específica destes em relação aos agregados maiores, para densidades semelhantes, enquanto a maior concentração de K nos agregados maiores foi atribuída à absorção endógena eexógena.

Baver (1952) citou que, em solos ácidos, o efeito do Ca na agregação não é tão importante, porque solos saturados por $\mathrm{H}^{+}$floculam mais que solos saturados por $\mathrm{Ca}^{2+}$. Em solos alcalinos, o efeito do Ca pode ser constatado, pois ele toma olugar do $\mathrm{Na}$ no complexo de troca, e o $\mathrm{Na}$ é reconhecidamente um agentedispersante (Rengasamy \& Olsson, 1991).

O Fe hidratado, quando presente no solo, tem forte poder de agregá-lo. No entanto, na presença de grandes concentrações de Fe já se observou que esse elemento causa a dispersão das argilas, pois, ao revestir sua superfície, altera-Ihes a carga (Shanmuganathan \& Oades, 1982). Bartoli et al. $(1992 a, b)$ descreveram clara relação entre a estabilidade estrutural eo Feadsorvido, verificando também que substâncias húmicas, na ausência de tal cátion, não foram agentes agregantes efetivos. J anczuk et al. (1992) verificaram que tanto o aumento de F e quanto o de Al causam aumento das 
forças de atração dos colói des que influenciam a agregação do solo.

O método de análise dos agregados tem por objetivo determinar a quantidade e a distribuição do tamanho de agregados estáveis em água. Esse método caracteriza-se pela agitação lenta, dentro de água, de uma amostra de solo, por tempo determinado. As frações das amostras que permanecem em uma ou várias classes detamanho são usadas para descrever a condição estrutural da amostra inicial do solo. Para a escala de partículas de diâmetro igual ao das argilas e silte, os métodos geralmente consistem em caracterizar, por densitometria e turbidimetria, a suspensão resultante da exposição dos agregados a forças destrutivas (Angers \& Mehuis, 1993).

O objetivo destetrabal ho foi verificar a influência de atributos físicos, quími cos e biológi cos, tais como: teores de matéria orgânica, de bases, de argila dispersa em água e total, carbono da biomassa microbiana e números de fungos e bactérias, na estabilidade de agregados em água de dois Latossol os sob plantio di reto há mais de quatroanos.

\section{MATERIAL E MÉTODOS}

\section{Caracterização das áreas experimentais}

\section{Latossolo Vermelho - LVd-CNP}

Esta área, na Fazenda Lagoa Velha, localiza-se no município de Campos Novos Paulista

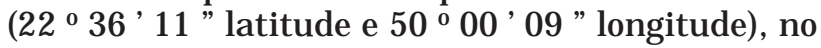
oeste do estado de São Paulo. A área do experimento tem aproximadamente 35 ha, localizada em uma encosta de $400 \mathrm{~m}$ de largura por $880 \mathrm{~m}$ de comprimento, sendo a maior dimensão na direção do declive. O solo, segundo o Sistema Brasileiro de Classificação (E mbrapa, 1999), é um Latossolo Vermelho distrófico típico álico textura média $A$ moderado. O clima da região, segundo a dassificação deKöppen, é do ti po Cfa, tropical úmido sem estação seca, com verões quentes, geadas pouco freqüentes, tendência de concentração das chuvas nos meses de verão e com regime de chuva de $1.200 \mathrm{~mm}^{2} \mathrm{no}^{-1}$ (Setzer, 1966). A cultura da safra de verão é soja (Glycinemax (L.) Merrill), com milho "safrinha" (Zea mays L.), na safra de inverno, e, eventualmente, milheto (Pennisetum typhoides Burm. F.), na primavera, todas em plantio direto desde 1995.

\section{Latossolo Vermel ho - LVd-Anga}

Localiza-se em Angatuba (23 $29^{\prime}$ ' $23^{\prime \prime}$ latitude e 48 ० $24^{\prime} 46^{\prime \prime}$ longitude), no sul do estado de São Paulo. A área experimental tem 90 ha e é irrigada por meio de um pivô-central cujo raio atinge $500 \mathrm{~m}$. O solo é um Latossolo Vermelho distrófico típicoálico textura argilosa A moderado, segundo o Sistema
Brasileirode Classificação (Embrapa, 1999). O clima da região, segundo a classificação de Köppen, é do tipo Cfa mesotérmico úmido, sem estação seca bem definida, e com regime de chuva de $1.250 \mathrm{~mm}^{2} \mathrm{ano}^{-1}$ (Setzer, 1966). As culturas em rotação envolvem soja (Glycinemax (L.) Merrill), milho (Zea mays L.) e batata (Solanum tuberosum L.), esta última introduzida na área a cada três anos e com cultivo convencional.

\section{Demarcação das áreas experimentais}

A demarcação do contorno das áreas experimentais foi feita com um DGPS com precisão submétrica, a partir da qual foi definida a grade de amostragem, com pontos distanciados de $100 \mathrm{~m}$, num total de 37 pontos de amostragem no LVd-CNP e de 76 pontos no LVd-Anga (Figura 1 ).

Após a colheita da cultura de verão, segundo a grade de amostragem georreferenciada, retiraramse as amostras de solo, na profundidade de $0-10 \mathrm{~cm}$, para a análise dos atributos físicos, químicos e biológicos, em maio de 2000.

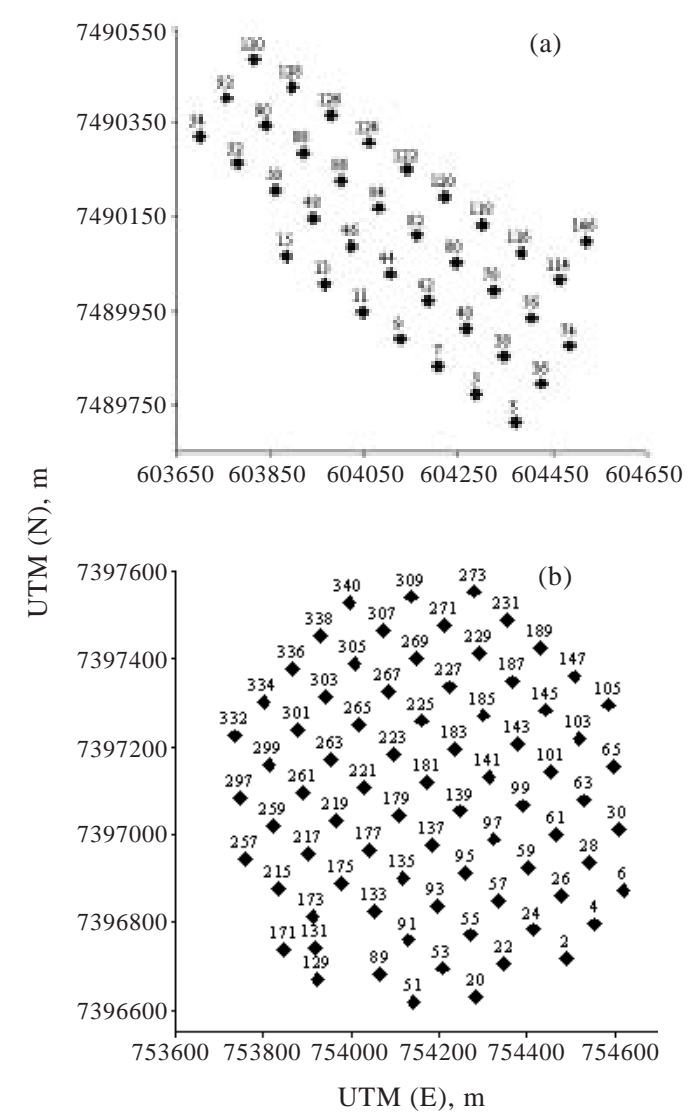

Figura 1. Grade de amostragem no Latossolo Vermelho distrófico típico álico textura média A moderado, em Campos Novos Paulista, SP (a), e no Latossolo Vermelho distrófico típico álico textura argi losa A moderado, em Angatuba, SP (b), com coordenadas em UTM (Zona 22). 


\section{Análise de estabilidade de agregados por via úmida}

O método empregado é basicamente o descrito por Kemper \& Chepil (1965), com modificações introduzidas pelo Laboratório de Física do Solo do Instituto Agronômico.

No laboratório, as amostras são espalhadas e suavemente destorroadas sobre bandejas forradas com papel. O peneiramento das amostras secas ao ar éfeitoem agitador mecânico com as peneiras 9,52, 4,00 e 2,00 mm e com o fundo, pel o tempo de $10 \mathrm{~min}$, na rotação máxima do aparelho. A fração menor que $2,00 \mathrm{~mm}$ (TFSA) é separada para a análise de distribuição de tamanho de partículas.

Para determinar a umidade das amostras, $25 \mathrm{~g}$ de agregados da classe 9,52 a 4,00 mm de diâmetro, em duplicata, são pesados e colocados em estufa a 105-110 ㄷ. A massa de matéria seca é obtida após $48 \mathrm{~h}$.

Os recipientes em que se processam as amostras são chei os com água em nível suficiente para cobrir a peneira superior durante o peneiramento. As amostras utilizadas para tal estudo, em triplicata, têm $50 \mathrm{~g}$ de agregados que, antes de irem para o conjunto de peneiras, sofrem os prétratamentos: (a) com água, (b) com álcool e (c) com benzeno (Hénin et al., 1976). Durante $10 \mathrm{~min}$, as amostras são gentilmente umedecidas, pelas bordas, com água, com álcool ou com benzeno, conforme o prétratamento. O peneiramento é feito com peneiras de malhas de 7,93, 6,35, 4,00, 2,00, 1,00 e 0,50 mm de diâmetro, também durante 10 min.

Após o peneiramento, a série de peneiras é imediatamente removida do tanque, permitindo-se que a água escorra por alguns segundos. Os agr egados contidos em cada penei ra são transferidos para os respectivos copos com auxílio de pisseta e colocados a secar em estufa a $105-110{ }^{\circ} \mathrm{C}$ por $48 \mathrm{~h}$ ou até massa constante. Os copos mais os agregados são pesados, sendo tais val ores registrados como $\mathrm{T}+\mathrm{A}$.

Nos copos correspondentes às peneiras de 7,93, 6,35 e 4,00 mm de abertura de mal ha, passa-se um pincel para soltar os agregados que, a seguir, são umedecidos com água e desfeitos com bastonete de ponta de borracha. O material do copo é então passado pela mesma peneira previamente usada: por meio deum levejato deágua edo bastonete, partículas finas passam por ela, enquanto o material retido na peneira é seco, pesado e registrado como $T+P$.

O estado de agregação das amostras de solo é avaliado pelo índice de diâmetro médio ponderado (DMP) e pela percentagem de agregados estáveis em água em cada classe de distribuição.

O DMP é expresso da seguinte forma:

$$
\mathrm{DMP}=\sum_{i=1}^{n}(\mathrm{Xi} \times \mathrm{Wi})
$$

em que
Wi $=$ proporção de cada classe em relação ao total

$\mathrm{Xi}=$ diâmetro médio das classes de agregados $(\mathrm{mm})$

$\mathrm{n}=$ número de classes de agregados

\section{Argila total e dispersa em água}

Para a determinação da argila total, emprega-se o método da pi peta, que é o usado no Laboratório de F ísica do Sol o do I nstituto Agronômi co eestá descrito em Camargo et al. (1986). A fração menor que 2,00 mm (TFSA) éutilizada para essa determinação, e o dispersante químico é uma mistura de hidróxido de $\mathrm{Na}$ e hexametafosfato de $\mathrm{Na}$.

A quantidade de argila dispersa em água é determinada pelo mesmo método, excluindo-se o uso do dispersante. Para isso, os agregados da classe 9,52 a 4,00 mm são moídos e passados por peneira de $2,00 \mathrm{~mm}$.

Após ambas as determinações, calcula-se o grau defloculação e de dispersão das amostras, conforme Camargo et al. (1986).

\section{Atributos químicos}

O princípio do método de determinação da matéria orgânica do solo é sua oxidação por solução de dicromato de $\mathrm{Na}$ em ácido sulfúrico a frio, seguida de determinação colorimétrica do cátion crômio proveniente da reação de oxidação e comparação desses valores com resultados de amostras cujos teores de matéria orgânica foram avaliados pelo método de Walkley-Black (Raij et al., 2001).

$\mathrm{O}$ pH é determinado em solução $0,01 \mathrm{~mol} \mathrm{~L}^{-1}$ de $\mathrm{CaCl}_{2}$. A acidez total $(\mathrm{H}+\mathrm{Al})$ é estimada a partir dos valores de $\mathrm{pH}$ de uma suspensão do solo em solução-tampão (Raij et al., 2001).

Para calcular a percentagem de saturação por bases, procede-se à determinação dos teores de $\mathrm{Ca}$, $\mathrm{Mg}, \mathrm{K}$ eNa pela extração com uma resina trocadora de íons. O princípio do método éa transferência de $\mathrm{Ca}, \mathrm{Mg}, \mathrm{K}$ e $\mathrm{P}$ para a resina trocadora de íons, em meio aquoso. A seguir, éfeita a separação de resina do solo e extração dos el ementos da resina com solução ácida de cloreto de Na (Raij et al., 2001).

Os micronutrientes ( $\mathrm{Cu}, \mathrm{Fe}, \mathrm{Mn}$ e $\mathrm{Zn}$ ) são extraídos utilizando a sol ução complexantedo DTPA em pH 7,3, e determinados por espectrometria de emissão atômica por plasma. Extrai-se oB em água aquecida em forno de mi croondas e com uma sol ução de cloreto de $\mathrm{Ba} 1,25 \mathrm{~g} \mathrm{~L}^{-1}$. A determinação é por espectrometria de emissão atômica por plasma (Raij et al, 2001).

\section{Quantificação dos microrganismos}

A quantificação dos microrganismos é feita pelo método de diluição em placas. Dez gramas de solo 
são suspensos em $90 \mathrm{~mL}$ de sol ução esterilizada de $0,01 \mathrm{~mol} \mathrm{~L}^{-1}$ de $\mathrm{MgSO}_{4} \cdot 7 \mathrm{H}_{2} \mathrm{O}$ eagitados por cerca de 10 min. A partir dessa suspensão, são preparadas diluições, de fator 10, em tubos de ensaio com a mesma solução. Alíquotas de $0,1 \mathrm{~mL}$ das diluições são espalhadas em placas de Petri com o meio de cultura adequado para o microrganismo que se deseja contar. Para fungos utilizou-se o meio de Martin e, para bactériastactinomicetos, o meio de extrato de solo. As placas são colocadas em incubadora a $28^{\circ} \mathrm{C}$ e, quando se detecta visualmente o crescimento, contam-se as col ônias de cada grupo microbiano. O resultado é dado em unidades formadoras de colônias (ufcs).

O carbono da biomassa microbiana é avaliado pelo método da fumigação-extração, de acordo com Vance et al. (1987), que se baseia no fato de que o carbono dos microrganismos mortos pela fumigação é liberado para o solo, de onde é possível extraí-lo quimicamente. Subamostras fumigadas e não fumigadas são submetidas à extração com $\mathrm{K}_{2} \mathrm{SO}_{4}$ (0,5 mol L-1), por $2 \mathrm{~h}$ sob agitação, e, depois, são centrifugadas e filtradas. O sobrenadante recebe $\mathrm{K}_{2} \mathrm{Cr}_{2} \mathrm{O}_{7}$ e $\mathrm{H}_{2} \mathrm{SO}_{4}$, oxidando o carbono. O excesso de dicromato é titulado com $\mathrm{Fe}\left(\mathrm{NH}_{4}\right)\left(\mathrm{SO}_{4}\right)$, a partir do qual se pode calcular a quantidade de carbono extraído na amostra.

\section{Análises estatísticas}

Os dados foram analisados por meio de regressões lineares múltiplas entreo DMP eos atributos físicos, químicos e biológicos determinados, usando o procedimento "stepwise" do programa computacional Minitab (Minitab, 2000), a 15 \% de significância para entrada e manutenção de variáveis no processo.

\section{RESULTADOS E DISCUSSÃO}

Os dados da análise granulométrica (Quadro 1) confirmam a textura franco-arenosa para a camada superficial do Latossolo de Campos Novos Paulista e muito argilosa para a do de Angatuba.

Quadro 1. E statísticas dos atributos físicos, químicos e biológi cos do Latossolo Vermel ho distrófico típico álico textura média A moderado (LVd-CNP) e do Latossolo Vermelho distrófico típico álico textura argilosa A moderado (LVd-Anga)

\begin{tabular}{|c|c|c|c|c|}
\hline \multirow{2}{*}{ Atributo profundidade $(0-10 \mathrm{~cm})$} & \multicolumn{2}{|c|}{ LVd-CNP } & \multicolumn{2}{|c|}{ LVd-Anga } \\
\hline & Média & CV (\%) & Média & CV (\%) \\
\hline Areia grossa $\left(\mathrm{g} \mathrm{kg}^{-1}\right)$ & 364 & 13 & 54 & 17 \\
\hline Areia fina $\left(\mathrm{g} \mathrm{kg}^{-1}\right)$ & 407 & 8 & 128 & 21 \\
\hline Areia total $\left(\mathrm{g} \mathrm{kg}^{-1}\right)$ & 771 & 3 & 181 & 18 \\
\hline Silte $\left(\mathrm{g} \mathrm{kg}^{-1}\right)$ & 50 & 19 & 146 & 16 \\
\hline Argila $\left(\mathrm{g} \mathrm{kg}^{-1}\right)$ & 179 & 9 & 672 & 6 \\
\hline Argila disp. $\mathrm{H}_{2} \mathrm{O}\left(\mathrm{g} \mathrm{kg}^{-1}\right)$ & 94 & 14 & 422 & 9 \\
\hline Grau de floculação (\%) & 47 & 13 & 37 & 13 \\
\hline Grau de dispersão (\%) & 53 & 12 & 63 & 8 \\
\hline Matéria orgânica ( $\left.\mathrm{g} \mathrm{dm}^{-3}\right)$ & 21 & 17 & 32 & 12 \\
\hline $\mathrm{pH}$ & 6,1 & 3 & 5,4 & 6 \\
\hline$P\left(\mathrm{mg} \mathrm{dm}^{-3}\right)$ & 57 & 41 & 37 & 77 \\
\hline $\mathrm{K}+\left(\mathrm{mmol}_{\mathrm{c}} \mathrm{dm}^{-3}\right)$ & 1,5 & 34 & 3,1 & 28 \\
\hline $\mathrm{Ca}^{2+}\left(\mathrm{mmol}_{\mathrm{c}} \mathrm{dm}^{-3}\right)$ & 36 & 18 & 37 & 49 \\
\hline $\mathrm{Mg}^{2+}\left(\mathrm{mmol}_{\mathrm{c}} \mathrm{dm}^{-3}\right)$ & 14 & 22 & 18 & 88 \\
\hline $\mathrm{H}+\mathrm{Al}\left(\mathrm{mmol}_{\mathrm{c}} \mathrm{dm}^{-3}\right)$ & 14,8 & 13 & 36,3 & 20 \\
\hline Soma bases $\left(\mathrm{mmol}_{\mathrm{c}} \mathrm{dm}^{-3}\right)$ & 52 & 18 & 59 & 58 \\
\hline CTC $\left(\mathrm{mmol}_{\mathrm{c}} \mathrm{dm}^{-3}\right)$ & 67 & 13 & 95 & 32 \\
\hline V (\%) & 77 & 6 & 60 & 17 \\
\hline$B\left(\mathrm{mg} \mathrm{dm}^{-3}\right)$ & 0,2 & 32 & 0,5 & 18 \\
\hline $\mathrm{Cu}\left(\mathrm{mg} \mathrm{dm}^{-3}\right)$ & 0,4 & 22 & 1,4 & 14 \\
\hline $\mathrm{Fe}(\mathrm{mg} \mathrm{dm}-3)$ & 16,2 & 20 & 20,5 & 23 \\
\hline $\mathrm{Mn}\left(\mathrm{mg} \mathrm{dm}^{-3}\right)$ & 2,5 & 38 & 3,3 & 95 \\
\hline $\mathrm{Zn}\left(\mathrm{mg} \mathrm{dm} \mathrm{dm}^{-3}\right)$ & 1,7 & 148 & 1,5 & 29 \\
\hline CBM $\left(\mu \mathrm{gC} \mathrm{g}^{-1}\right)$ & 661 & 15 & 540 & 44 \\
\hline Fungos (ufcs) & $1,91.10^{5}$ & 96 & $7,86.10^{4}$ & 75 \\
\hline Bactérias (ufcs) & $1,54.10^{7}$ & 81 & $1,15.10^{7}$ & 55 \\
\hline
\end{tabular}

$\overline{\mathrm{CV}}=$ coeficiente de variação. CBM = carbono da biomassa microbiana. 
Os resultados relativos à análise química (Quadro 1) do LVd-CNP evidenciaram a adubação queé aplicada às culturas: teor de matéria orgânica dentro do esperado, acidez muito baixa, altos teores de $\mathrm{P}, \mathrm{Ca}^{2+}, \mathrm{Mg}^{2+}, \mathrm{Fe}$ e $\mathrm{Zn}$, médios para saturação por bases, Cu e Mn ebaixos para K+eB. Quanto ao LVd-Anga, o teor de matéria orgânica foi também dentro do esperado, acidez média, altos teores de $\mathrm{K}^{+}, \mathrm{Ca}^{2+}, \mathrm{Mg}^{2+}, \mathrm{Cu}, \mathrm{Fe}$ e $\mathrm{Zn}$ e médios para $\mathrm{P}$, saturação por bases, $\mathrm{B}$ e Mg.

Os pré-tratamentos apresentaram valores bastante semel hantes entre si para a estabilidade de agregados no LVd-CNP (Quadro 2). No LVdAnga, no entanto, a variação entre o mai or - obtido com o pré-tratamento em álcool - e o menor - obtido com o benzeno - foi de quase 10 vezes, examinandose o DMP, por exemplo.

A camada superficial do LVd-CNP é franco-arenosa com teor médio de areia total de $771 \mathrm{~g} \mathrm{~kg}^{-1}$, enquanto a do LVd-Anga é argilosa com teor médio de areia total de $181 \mathrm{~g} \mathrm{~kg}^{-1}$. Considerando, principalmente, essa diferença em textura, ocorre a diferença entre os índices de estabilidade de agregados nos dois sol os com pré-tratamento com água. Outro fator que estaria influindo na maior agregação do LVdAnga é a concentração de cátions e de matéria orgânica, que agem como agregantes do solo. A percentagem de agregados estáveis entre 6,35 e 0,50 mm foi de 4,1, no LVd-CNP, enquanto, no LVd-Anga, foi de 50,1. O diâmetro médio ponderado foi de 0,281, no LVd-CNP, e, no LVd-Anga, foi de 1,159.

O álcool atenuou de forma drástica a dispersão dos agregados no LVd-Anga e no LVd-CNP notouse um pequeno acréscimo do DMP com este prétratamento, mostrando que este não dissolve frações orgânicas de grande importância para a agregação do solo; deve agir como um desidratante principalmente nos microporos dos agregados aproximando a fração orgânica produzida pela população bacteriana, visto que neste prétratamento observou-se seu aumento. Também deve agir como um atenuador da pressão que a água exerce ao penetrar nos agregados mantendo-os unidos. Deve-se ressaltar que, no LVd-Anga, a ação da matéria orgânica evidenciada no pré-tratamento com água não foi constatada no pré-tratamento com álcool que, por sua vez, evidenciou a ação bacteriana, levando a crer que o álcool deve solubilizar parte da fração húmica do solo.

O benzeno agiu dissolvendo a matéria orgânica em todas as frações, principalmente no LVd-Anga. Ao que parece, em agregados entre 2,00 e 0,50 mm, o benzeno não agiu com a mesma eficácia que nas classes de agregados maiores, pois no LVd-CNP estavam presentes apenas agregados nesta classee não houve grande diferença entre as amostras com relação à estabilidade, podendo este fenômeno estar ocorrendo pela mai or área superficial dos agregados maiores e, conseqüentemente, pela maior possibilidade de penetração do líquido nos agregados. No LVd-Anga, a diferença dos índices da estabilidade de agregados entre os prétratamentos foi drástica.

O DMP no prétratamento com água no LVdAnga foi de 1,2 mm, enquanto para o LVd-CNP foi de 0,3 mm. Seguramente essa diferença está relacionada com a grande diferença textural (Baver, 1952; M bagwu et al., 1993; Boix-Fayos et al., 2001) entre ambos. No LVd-CNP, os valores médios encontrados foram de $179 \mathrm{~g} \mathrm{~kg}^{-1}$ e $21 \mathrm{~g} \mathrm{dm}^{-3}$, para o teor de argila e matéria orgânica, respectivamente, e, para o LVD-Anga, foram de $672 \mathrm{~g} \mathrm{~kg}^{-1}$ e $32 \mathrm{~g} \mathrm{dm}^{-3}$ (Quadro 1).

Quadro 2. Percentagem de agregados estáveis em água no Latossolo Vermelho distrófico típico álico textura média A moderado e no Latossolo Vermelho distrófico típico álico textura argil osa A moderado submetidos a pré-tratamentos com água, álcool e benzeno

\begin{tabular}{|c|c|c|c|c|c|c|c|c|}
\hline \multirow{2}{*}{ Pré-tratamento } & \multicolumn{8}{|c|}{ Classe de agregado } \\
\hline & 9,52 a 7,93 & 7,93 a 6,35 & 6,35 a 4,00 & 4,00 a 2,00 & 2,00 a 1,00 & 1,00 a 0,50 & $<0,50$ & DMP \\
\hline & \multicolumn{8}{|c|}{ Latossolo Vermelho distrófico típico álico textura média A moderado } \\
\hline Água & 0 & 0 & 0 & 0,3 & 0,6 & 3,2 & 95,9 & 0,281 \\
\hline Álcool & 0 & 0,1 & 0,2 & 0,5 & 0,8 & 3,1 & 95,3 & 0,305 \\
\hline \multirow[t]{2}{*}{ Benzeno } & 0 & 0,1 & 0,2 & 0,4 & 0,3 & 1,8 & 97,2 & 0,292 \\
\hline & \multicolumn{8}{|c|}{ Latossolo Vermel ho distrófico típico álico textura argilosa A moderado } \\
\hline Água & 0 & 0,1 & 1,9 & 16,8 & 23 & 11,6 & 46,6 & 1,159 \\
\hline Álcool & 2,9 & 9,6 & 21 & 17,4 & 7,7 & 5,5 & 35,9 & 2,796 \\
\hline Benzeno & 0 & 0 & 0,1 & 0,5 & 1,2 & 2,2 & 96 & 0,295 \\
\hline
\end{tabular}




\section{Latossolo Vermelho - LVd-CNP}

\section{Pré-tratamento com água}

O DMP é um índice que traduz a estabilidade dos agregados de toda a amostra. Sendo assim, a análise dos atributos que concorrem para seu aumento ou diminuição é uma síntese de todos os fatores que influenciaram cada classe de agregados.

A comunidade bacteriana age tanto mecanicamente, pelo aumento do número de indivíduos em microporos do solo, queligam a fração mineral, aproximando-a e reorganizando-a de maneira a formar agregados, como quimicamente, pela produção de polissacarídeos (F oster, 1978).

Agregados estabilizados por polissacarídeos não têm grande durabi lidadeno solo, já que tais compostos serão consumidos por outros microrganismos. Essa atividade, ao mesmo tempo, acelera a degradação das substâncias orgânicas novas no solo, como, por exemplo, os carboidratos, em substâncias mais estáveis, como as húmicas, que são as responsáveis pela formação de agregados persistentes no solo (Tisdall \& Oades, 1982).

À semelhança dos resultados apresentados por outros autores (Bartoli et al., 1992a,b), modelos propostos por De Coninck (1980) e teorias e resultados citados em Russel (1973) eArena (1968), oF etambém foi fator determinante para a agregação neste estudo (Quadro 3).

\section{Pré-tratamento com álcool}

Comparando os pré-tratamentos com água ecom álcool (Quadro 4), observa-se que, com o álcool, desaparece o efeito de agregação do K e aparecem a argila como agregante e o efeito desagregante da areia fina. Os dois pré-tratamentos confirmaram a atuação do $\mathrm{Fe}$ e da comunidade bacteriana como elementos de agregação.

O pré-tratamento com álcool evidencia a argila como o fator mais importante a aumentar a estabilidade dos agregados. Em relação às frações mais grosseiras do solo, ela é, sabidamente, um

Quadro 3. Atributos mais importantes na regressão linear múltipla entre o diâmetro médio ponderado do Latossolo Vermelho distrófico típico álico textura média A moderado, usando água como pré-tratamento, e os atributos físicos, químicos e biológicos do solo

\begin{tabular}{lcc}
\hline Atributo & Coeficiente & Probabilidade \\
\hline Bactérias (ufcs) & $4.10-10$ & 0,002 \\
Ferro $\left(\mathrm{mg} \mathrm{dm}^{-3}\right)$ & 0,00142 & 0,011 \\
Potássio $\left(\mathrm{mmol}_{\mathrm{c}} \mathrm{dm}^{-3}\right)$ & 0,0073 & 0,031
\end{tabular}

Diâmetro médio ponderado $(\mathrm{mm})=0,2412+4 \cdot 10^{-10}$ Bactérias + 0,00142 Ferro $+0,0073$ Potássio. $R^{2}$ ajustado $=0,3874$.
Quadro 4. Atributos mais importantes na regressão linear múltipla entre o diâmetro médio ponderado dos agregados do Latossolo Vermelho distrófico típico álico textura média A moderado, usando álcool como prétratamento, e atributos físicos, químicos e biológicos do solo

\begin{tabular}{lcc}
\hline \multicolumn{1}{c}{ Atributo } & Coeficiente & Probabilidade \\
\hline Argila $\left(\mathrm{g} \mathrm{kg}^{-1}\right)$ & 0,00131 & $<10^{-3}$ \\
Grau de dispersão (\%) & 0,00257 & $<10^{-3}$ \\
Ferro (mg dm $\left.{ }^{-3}\right)$ & 0,0040 & 0,010 \\
Areia fina $\left(\mathrm{g} \mathrm{kg}^{-1}\right)$ & $-0,00030$ & 0,046 \\
Bactérias (ufcs) & $6.10^{-9}$ & 0,117 \\
\hline
\end{tabular}

Diâmetro médio ponderado $(\mathrm{mm})=-0,1139+0,00131$ Argila + 0,00257 Grau de dispersão $+0,0040$ Ferro $-0,0003$ Areia fina $+6.10^{-9}$ Bactérias. $R^{2}$ ajustado $=0,5713$.

agente agregante por apresentar muita energia livre e maior superfície específica por unidade de volume (Tschapek, 1949). Os resultados obtidos corroboram os de M bagwu et al. (1993) e Boix-F ayos et al. (2001). Saliente-se que a presença de agregados neste solo de textura média deve-se unicamente ao efeito cimentante das frações: argila e orgânica (Dutartre et al., 1993), que unem as frações silte e areia, pois partículas grosseiras do solo, sozinhas, estão em permanente estado de defloculação (Baver, 1952).

Como agentes agregantes também aparecem o Fe e a comunidade bacteriana, cuja importância já havia si do revelada no pré-tratamento com água. $\mathrm{O}$ Fe é um elemento trival ente e reconhecidamente um forte agente agregante do solo (Shanmuganathan \& Oades, 1982; Bartoli et al., 1992a,b; J anczuk et al., 1992). Na série liotrópica de Arena (1968), esse elemento aparece como o segundo mais importante na série floculante, em seguida aoAl. Sabe-se que o intumescimento, a quebra deagregados ea dispersão de argila dependem, dentre outros fatores, da hidratação dos cátions. Assim, o Fe diminui com eficiência o potencial energético das moléculas de água (Arena 1968; I wata et al., 1988). Sendo um elemento trivalente, o Fe une-se à fração húmica para formar agregados estáveis, conformejá relatado por Edwards \& Bremer (1967). E ssas associações constituem grande parte da fração organomineral do solo (Tisdall \& Oades, 1982).

Sabe-se que os polissacarídeos produzidos por bactérias são, em grande parte, géis hidrófobos (Guggenberger et al., 1999) que, quando estão na superfície dos agregados, impedem a infiltração de água nos mi croporos ea destruição das ligações entre os colóides ea conseqüente destruição dos agregados (Hénin etal., 1976). Além da excreção de polissacarídeos, as bactérias agem mecanicamente no sistema organomineral do solo, visto que, quando suas 
colônias crescem, pressionama partemineral do solo que, por sua vez, se reorienta (F oster, 1978).

Os graus de dispersão e de floculação foram envolvidos no procedimento "stepwise", com o objetivo de verificar se essa técnica mais rápida poderia ser utilizada como procedimento para estimar a estabilidade deagregados. Os coeficientes de determinação, porém, foram muito baixos e observou-se efeito inverso do fenômeno, ou seja, houve correl ação positiva entre o grau de dispersão e os índices de agregação e correl ação negativa com o grau de floculação. I sso pode ser atribuído ao fato de que, quanto maior o teor de argila, maior a estabilidade de agregados. Entretanto, quando se determina a argila dispersa em água, nos solos que apresentam elevados teores de argila total, encontram-se, da mesma forma, maiores teores de argila dispersa em água. Com rel ação a esseassunto há necessidade de mais estudos.

Angers \& Mehuis (1993) citaram que a técnica para determinar a argila dispersa é eficiente para partículas do tamanho de argila esilte. Oades (1984) relatou quea matéria orgânica do sol o provoca maior dispersão deargila pela complexação deíons metálicos di e trivalentes, reduzindo suas concentrações na solução e aumentando a dupla camada elétrica. A matéria orgânica, comofoi um dos principais agentes para a estabilização dos agregados, pode estar provocando o efeito inverso dos métodos aplicados. Ressalte-se também que a argila dispersa em água é diretamente proporcional ao grau de dispersão e inversamente proporcional ao de floculação.

A areia fina é fator de desestabilização dos agregados do sol o, o que pode ser verificado pel o sinal negativo do coeficiente. Isso podeser notado, também, por sua característica bem definida de aumentar a erodibilidade dos solos (Wischmeier \& Smith, 1978). Os dados encontrados nestetrabal ho corroboram os obtidos por Mbagwu et al. (1993). Aliada a essa característica, Russel (1973) observou que a fração areia fina éum meio desfavorável para o crescimento radicular, visto quequalquer canal ou poroformado em tal condição será obstruído pel o desmoronamento dos grãos de areia ao ser umedecido.

\section{Pré-tratamento com benzeno}

O que se observa com este pré-tratamento (Quadro 5), de maneira geral, éa ausência do efeito da comunidade bacteriana na agregação do solo, diferentemente do que ocorreu nos pré-tratamentos com ál cool eágua. O benzeno age como solventedos polissacarídeos excretados por bactérias ou outros organismos do solo, já que é um solvente orgânico (E duardo Vitoria, 1940; Fieser \& Fieser, 1948). Esse tratamento foi útil pois, desaparecendo o efeito da comunidade bacteriana, pôde-se constatar o efeito da de fungos, pel o enlace das partículas primárias e secundárias do solo, formando e estabilizando os agregados (Foster, 1981; Tisdal \& Oades, 1982; Guggenberger et al., 1999).
A participação da areia grossa como arcabouço da agregação explica sua inclusão entre os agentes da estabilização dos agregados. Este resultado vai ao encontro dos obtidos por M bagwu et al. (1993), que relacionaram a areia grossa com a maior responsável pela estabilidade de agregados.

Outro fato que deve ser ressaltado é a presença da matéria orgânica agindo como agregante, o que corrobora inúmeros trabalhos, como os de Silva \& Mielnickzuck (1997), Castro Filho et al. (1998) e Palmeira et al. (1999). Além desse efeito, há que se lembrar quea matéria orgânica éfonte de energia e nutrientes para a maioria dos microrganismos que ocorrem em solos cultivados.

\section{Latossolo Vermelho - LVd-Anga}

\section{Pré-tratamento em água}

Dentre os atributos importantes para a agregação desse sol o destacam-se a areia fina e a comunidade defungos, como desagregantes, ea matéria orgânica, como agregante (Quadro 6).

À semelhança do já observado para o LVd-CNP, a presença de elevados teores de areia fina e

Quadro 5. Atributos mais importantes na regressão linear múltipla entre o diâmetro médio ponderado do Latossolo Vermelho distrófico típico álico textura média A moderado, usando benzeno como pré-tratamento, e os atributos físicos, químicos e biológicos do solo

\begin{tabular}{llc}
\hline \multicolumn{1}{c}{ Atributo } & Coeficiente & Probabilidade \\
\hline Matéria orgânica $\left(\mathrm{g} \mathrm{dm}^{-3}\right)$ & 0,0042 & $<10^{-3}$ \\
Areia grossa $\left(\mathrm{g} \mathrm{kg}^{-1}\right)$ & 0,00025 & 0,006 \\
Fungos (ufcs) & 0,00004 & 0,079 \\
Ferro (mg dm-3) & 0,0022 & 0,094 \\
\hline
\end{tabular}

Diâmetro médio ponderado $(\mathrm{mm})=0,0688+0,0042$ Matéria orgânica $+0,00025$ Areia grossa $+0,00004$ Fungos $+0,0022$ Ferro. $R^{2}$ ajustado $=0,5184$.

Quadro 6. Atributos mais importantes na regressão linear múltipla entre o diâmetro médio ponderado dos agregados do Latossolo Vermelho distrófico típico álico textura argilosa A moderado, usando água como prétratamento, e os atributos físicos, químicos e biológicos do solo

\begin{tabular}{lcc}
\hline \multicolumn{1}{c}{ Atributo } & Coeficiente & Probabilidade \\
\hline Areia fina $\left(\mathrm{g} \mathrm{kg}^{-1}\right)$ & $-0,00291$ & $<10^{-3}$ \\
Matéria orgânica $\left(\mathrm{g} \mathrm{dm}^{-3}\right)$ & 0,0144 & 0,001 \\
Fungos (ufcs) & $-0,00048$ & 0,093 \\
\hline
\end{tabular}

Diâmetro médio ponderado $(\mathrm{mm})=1,105-0,00291$ Areia Fina $+0,0144$ Matéria orgânica-0,0048 Fungos. $R^{2}$ ajustado $=0,3522$. 
conseqüente diminuição dos de argila, agiu negativamente sobre a estabilidade estrutural do solo. Nesse solo, a matéria orgânica foi importante para a estabilidade de agregados, o que corrobora trabalhos de Harris et al. (1966) e Edwards \& Bremer (1967), que verificaram que a matéria orgânica é muito mais eficiente em solos argilosos do que em sol os com maiores teores de areia, como, por exemplo, oL Vd-CNP. Nesse último solo, notouse que a comunidade bacteriana foi mais eficiente em agregar o solo que a matéria orgânica. Essa aparente discrepância talvez esteja relacionada com a menor comunidade de bactérias e com uma concentração maior da matéria orgânica no LVdAnga, que estaria escondendo o efeito de polissacarídeos bacterianos.

A comunidade de fungos aparece também como agente desagregante, o que é um dado para ser avaliado com cuidado: vários são os autores que citam a importância dos fungos na formação e estabilização de agregados pela excreção de polissacarídeos e principal mente por suas hifas, que enlaçam partículas primárias ou até mesmo agregados, aproximando-os e estabilizando-os (Harris et al., 1966; F oster, 1981; Tisdall \& Oades, 1982; Molope, 1987; Guggenberger et al., 1999). É possível que os resultados aqui apresentados estejam relacionados com um menor comprimento de hifas por unidade de volume de solo, insuficiente para estabilizar os agregados (Degens et al., 1994). Outro fato que deve ser ressaltado é que a capacidade de agregação exercida pel os fungos depende da espécie (Harris et al., 1966; Degens, 1997). F atores como $\mathrm{pH}$, umidade do solo, aeração, temperatura, composi ção química dos resíduos vegetais presentes no sol o e disponi bilidade de nutrientes no sol o podem não ser os ideais para o crescimento da comunidade de fungos (Harris et al., 1966) nesse solo, que, muito provavel mente, é qualitativamente diferente da que crescia no LVd-CNP.

A matéria orgânica é agente identificado como agregante(Hénin et al., 1976; Tisdall \& Oades, 1982; Degens, 1997; Castro Filho et al., 1998; Kay \& Angers, 1999). Porém, Tisdall \& Oades (1982) eK ay $\&$ Angers (1999) citam que, em al guns casos, ela pode agir como dispersante por apresentar cargas permanentes negativas, que, na ausência de cátions, podem repelir-se. O resultado aqui apresentado confirma os da maioria dos autores citados. A eficiência da matéria orgânica para a estabilização de agregados pode ser verificada por diferentes formas de manejo do solo que aumentam seu teor, como, por exemplo, o plantio direto (Campos et al., 1995; Castro Filhoet al., 1998) ea adição de resíduos orgânicos (Tisdall et al., 1978; J orge et al., 1991).

\section{Pré-tratamento com álcool}

Com o pré-tratamento com álcool (Quadro 7), evidenciou-se a importância de outros agentes agregantes além da matéria orgânica, quais sejam:
Fe e bactérias, cujo efeito estaria sendo por ela encoberto. O álcool solubiliza parte dessa matéria orgânica, provavelmente o ácido hematomelânico, como citado em Russel (1973) e F assbender (1980). Pode-se supor que, quando ocorrea desidratação dos agregados, as partículas orgânicas - polissacarídeos bacterianos, nesse caso - e a fração argila aproximam-se e, por meio de cátions, como o Fe, ocorre sua interação, formando agregados estáveis em água. Da mesma forma já discutida para o LVdCNP, a inclusão da areia grossa entre os agregantes resulta de seu papel como esquel eto da agregação.

O Ca, pela análise estatística realizada, mostrouse agente de desagregação nesse solo, fato para o qual não se encontrou paralelo na literatura. Também, como agente desagregante, notou-se o $\mathrm{H}+\mathrm{Al}$. Nesse solo, no pré-tratamento com água, não se constatou efeito de cátions trocáveis, como o K no L Vd-CNP, sobre a estabilização de agregados, o que pode estar relacionado com a grande quantidade de cargas positivas, que conferem às frações (argila e orgânica), cargas que vão de neutras a positivas (Shanmuganatham \& Oades 1982), dispersando os colóides. Ressalte-se aqui queambos, o H +Al eo Ca, em média, foram os cátions em maior concentração no solo e, provavelmente, onde essas concentrações foram mais elevadas, houve efeito inverso na estabilidade dos agregados. Pode ser também que o álcool tenha solubilizado determinadas frações orgânicas que retinham grande quantidade de cátions que, após o tratamento, ficaram em excesso no solo, dispersando-o. O efeito desidratante do álcool, ao mesmo tempo, aproximou os minerais de argilas saturados por cátions, aumentando sua força de repulsão.

Chama a atenção, nesse pré-tratamento (Quadro 8), a diferença defatores entre os dois sol os:

\section{Quadro 7. Atributos mais importantes na regressão linear múltipla entre o diâmetro médio ponderado dos agregados do Latossolo Vermelho distrófico típico textura argilosa A moderado, usando álcool como pré-tratamento, e os atributos físicos, químicos e biológicos do solo}

\begin{tabular}{lcc}
\hline \multicolumn{1}{c}{ Parâmetro } & Coeficiente & Probabilidade \\
\hline Ferro $\left(\mathrm{mg} \mathrm{dm}^{-3}\right)$ & 0,0559 & $<10^{-3}$ \\
Bactérias $\left(\mathrm{ufcs}^{-3}\right.$ & 0,187 & 0,004 \\
$\mathrm{H}+\mathrm{Al}\left(\mathrm{mmol}_{\mathrm{c}} \mathrm{dm}^{-3}\right)$ & $-0,0282$ & 0,007 \\
Cálcio $\left(\mathrm{mmol}_{\mathrm{c}} \mathrm{dm}^{-3}\right)$ & $-0,0052$ & 0,053 \\
Areia grossa $(\mathrm{g} / \mathrm{kg})$ & 0,0090 & 0,059 \\
Fungos (ufcs) & $-0,0011$ & 0,098 \\
\hline
\end{tabular}

Diâmetro médio ponderado $=2,26+0,0559$ Ferro + 0,187 Bactérias - 0,0282 H +Al - 0,0052 Cálcio + 0,0090 Areia grossa 0,0011 Fungos. $R^{2}$ ajustado $=0,3164$. 
Quadro 8. Atributos mais importantes na regressão linear múltipla entre o diâmetro médio ponderado dos agregados do Latossolo Vermelho distrófico típico álico textura argilosa A moderado, usando benzeno como pré-tratamento, e os atri butos físicos, químicos e biológicos do solo

\begin{tabular}{lcc}
\hline \multicolumn{1}{c}{ Atributo } & Coeficiente & Probabilidade \\
\hline Areia fina $\left(\mathrm{g} \mathrm{kg}^{-1}\right)$ & $-0,00067$ & $<10^{-3}$ \\
Argila $\left(\mathrm{g} \mathrm{kg}^{-1}\right)$ & $-0,00041$ & $<10^{-3}$ \\
Potássio $\left(\mathrm{mmol}_{\mathrm{C}} \mathrm{dm}^{-3}\right)$ & 0,0076 & 0,009 \\
Saturação por bases $(\%)$ & $-0,00058$ & 0,023
\end{tabular}

Diâmetro médio ponderado $(\mathrm{mm})=0,6686-0,00067$ Areia fina - 0,00041 Argila + 0,0076 Potássio - 0,00058 Saturação por bases. $R^{2}$ ajustado $=0,2575$.

aqueles que apareceram como agregantes no LVdCNP - matéria orgânica, fungos e teor de $\mathrm{Fe}$ - não foram evidenciados no LVd-Anga. Nesse solo, o K também aparece como agente agregante, à semel hança do já ocorrido no LVd-CNP com o prétratamento com água. Sua importância para a agregação do solo foi maior que o $\mathrm{Ca}$ e $\mathrm{Mg}$, o que corrobora dados obtidos por Cecconi et al. (1963) e Ravina (1973). No entanto, o K apareceu como agente agregante no LVD-Anga apenas neste pré tratamento, ou seja, os polissacarídeos bacterianos, a matéria orgânica e o teor de Fe podem ter encoberto, com os outros pré-tratamentos, o efeito benéfico do $\mathrm{K}$. Foi um agente importante para a agregação na classe de agregados menores que 2,00 mm, visto que no LVd-CNP prevaleceram estes agregados e no LVd-Anga, neste prétratamento, também.

\section{CONCLUSÕES}

1. Para o LVd-CNP, na camada de $0-10 \mathrm{~cm}$, os principais agentes agregantes foram, em ordem de importância, a comunidade bacteriana e os teores de Fe e de K. Para o LVd-Anga, o principal agente agregante foi a matéria orgânica.

2. Pode-se esperar baixa estabilidade de agregados em solos com altos teores de areia fina, da mesma forma que se pode esperar alta estabilidade de agregados em sol os com al to teor de argila.

3. O K apareceu mais freqüentemente associado à agregação do sol o que o $\mathrm{Ca}$. O cátion mais eficiente para a estabilização de agregados foi o $\mathrm{Fe}$.

4. A comunidade bacteriana mostrou-se como o principal agente microbiano para a estabilização de agregados, aparecendo como principal agente no LVd-CNP e como um dos principais no LVd-Anga. J á os fungos não se mostraram tão eficientes.

\section{AGRADECIMENTOS}

Aos parcei ros do I nstituto Agronômico, os irmãos J osé Roberto e Lúcio Borges, proprietários da Fazenda L agoa Vel ha em Campos N ovos Paulista, e a Antônio Carlos Rodrigues eJ oséAntônio Furtado, proprietários da Fazenda Estância Dois I rmãos em Angatuba.

Às técnicas de laboratório, Luzia Aparecida Felisbino da Silva e Regina Célia Batista Moretti, e aos técnicos de campo, Márcio Fernando Mazzini e Reginaldo Galhardo Gonçalves, do Centro de Pesquisa e Desenvolvimento de Solos e Recursos Ambientais do I nstituto Agronômico, pela realização das análises de estabilidade de agregados e pela colaboração na coleta de amostras de solo.

\section{LITERATURA CITADA}

ANGERS, D.A. \& MEHUIS, G.R. Aggregate stability to water. In: CARTER, M.R., ed. Soil sampling and methods of analysis. Boca Raton, Lewis Publishers for the Canadian Society of Soil Science, 1993. p.651-657.

ARENA, A. Curso de suelos - Física de suelos. Rio de J aneiro: Centro Pan-Americano de Aperfeiçoamento para Pesquisas de Recursos Naturais (CEPERN), InstitutoPan-Americano de Geografia e História, OEA e Ministério da Agricultura do Brasil. 1968. 72p.

BARTOLI, F.; PHILIPPY, R. \& BURTIN, G. Poorly ordered hydrous Feoxides, colloidal dispersion and soil aggregation. II. Modification of silty soil aggregation with Fe (III) polycations and model humic macromolecules. J. Soil Sci., 43:59-75, 1992a.

BARTOLI, F.; PHILIPPY, R.; PORTAL, J .M. \& GERARD, B. Poorly ordered hydrous Fe oxides, colloidal dispersion and soil aggregation. I. Effect of humic macromolecules on surface and colloidal properties of Fe (III) polycations. J . Soil Sci., 43:47-58, 1992b.

BAVER, L.D. Soil physics. 2.ed. New York, J ohn Wiley \& Sons, 1952. $398 \mathrm{p}$.

BOIX-FAYOS, C.; CALVO-CASES, A.; IMESON, A.C. \& SORIANO-SOTO, M.D. Influence of soil properties on the aggregation of some Mediterranean soils and the use of aggregate size and stability as land degradation indicators. Catena, 44:47-67, 2001.

CAMARGO, O.A.; MONIZ, A.C.; J ORGE, J .A. \& VALADARES, J.M.A.S. Métodos de análise química e física de solos do Instituto Agronômico. Campinas, Instituto Agronômico, 1986. 94p. (Boletim técnico, 106) 
CAMARGO, O.A.; VALADARES, J.M.A.S. \& GERALDI, R.N. Características químicas e físicas de solo que recebeu vinhaça por longo tempo., Campinas, Instituto Agronômico, 1983. 30p. (Boletim técnico, 76)

CAMPOS, B.C.; REINERT, D.J .; NICOLODI, R.; RUEDELL, J . \& PETRERE, C. Estabilidade estrutural de um Latossolo Vermelho-Escuro distrófico após sete anos de rotação de culturas e sistemas de manejo de solo. R. Bras. Ci. Solo, 19:121-126, 1995.

CASTRO FILHO, C.; MUZILLI, O. \& PODANOSCHI, A.L. Estabilidade de agregados e sua relação com o teor de carbono orgânico num L atossolo Roxo distrófico, em função de sistemas de plantio, rotações de culturas e métodos de preparo das amostras. R. Bras. Ci. Solo, 22:527-538, 1998.

CECCONI, S.; SALAZRAND, A. \& MARTELLI, M. The effect of different cations on the structural stability of some soils. Agrochemica, 7:185-204, 1963.

CRUVINEL, P.E.; FLOCCHINI, R.G.; CRESTANA, S.; MORALES, J.R.; MIRANDA, J .; HUSKO, B.H.\& NIELSEN, D.R. Studying the influence of the aggregates sizes on some elements of an Oxisol with PIXE. Soil Sci., 155:100-104, 1993.

DE CONINCK, F. Major mechanisms in formation of spodic horizonts. Geoderma, 24:101-128, 1980.

DEGENS, B.P. Macro-aggregation of soils by biological bonding and binding mechanisms and the factors affecting these: a review. Aust. J . Soil Res., 35:431-459, 1997.

DEGENS, B.P.; SPARLING, G.P.\& ABBOT, L.K. The contribution from hyphae, roots and organic carbon constituents to the aggregation of a sandy loam under longterm clover-based and grass pastures. Europ. J . Soil Sci., 45:459-468, 1994.

DUTARTRE, Ph.; BARTOLI, F.; ANDREUX, F.; PORTAL, J .M. $\&$ ANGERS, A. Influence of content and nature of organic matter on the structure of some sandy soils from West Africa. In: BRUSSAARD, L. \& KOOISTRA, M.J ., eds. Soil structure/soil biota interrelationships. Amsterdam, Elsevier Science Publishers, 1993. p.459-478.

EDUARDO VITORIA, S.J. Química del carbono. Barcelona, Tipográfica Católica, 1940. 896p.

EDWARDS, A P. \& BREMER, J .M. Microaggregates in soil. J . Soil Sci., 18:64-73, 1967.

EMPRESA BRASILEIRA DE PESQUISA AGROPECUÁRIA EMBRAPA. Centro Nacional de Pesquisa de Solos. Sistema brasileiro de classificação de solos. Brasília, Embrapa, Produção de Informação; Rio de janeiro, Embrapa Solos, 1999. $412 \mathrm{p}$.

FASSBENDER, H.W. Química de suelos con énfasis en suelos de América Latina. San J osé, Costa Rica, Instituto Interamericano de Ciencias Agrícolas, 1980. 398 p.

FIESER, L.F . \& FIESER, M. Química orgánica. México, E ditorial Atlante, 1948. 1112p.

FOSTER, R.C. Mycelial strands of Pinus radiata D. Don: ultrastructure and histochemistry. New Phytol., 88:705711, 1981.
FOSTER, R.C. Ultrami cromorphology of some South Australian Soils. In: EMERSON, W.W.; BOND, R.D. \& DEXPER, A.R., eds. Modification of soil structure. New York, J ohn Wiley $\&$ Sons, 1978. p.103-109.

GUGGENBERGER, G.; ELLIOTT, E.T.; FREY, S.D.; SIX, J . \& PAUSTIAN, K. Microbial contributions to the aggregation of a cultivated grassland soil amended with starch. Soil Biol. Biochem., 31:407-419, 1999.

HARRIS, R.F.; CHESTERS, G. \& ALLEN, O.N. Dynamics of soil aggregation. Adv. Agron., 18:107-169, 1966.

HÉNIN, S.; GRAS, R. \& MONNIER, G. Os solos agrícolas. Rio deJ aneiro, Forense-Universitária; São Paulo, Universidade de São Paulo, 1976. 334p.

IWATA, S.; TABUCHI, T. \& WARKENTIN, B.P. Soil-water interactions: mechanisms and applications. New York, Marcell Dekker, 1988. 67p.

J ANCZUK, B.; BIALOPIOTROWICZ, A.; ZDZIENNICKA, M.; HAJ NOS, M. \& J ÓZEFACIUK, G. The influence of soil clay constituents on surface free energy of clay fractions. J . Soil Sci., 43:27-35, 1992.

J ORGE, J.A.; CAMARGO, O.A. \& VALADARES, J.M.A.S. Condições físicas de um $L$ atossol o Vermel ho-E scuro quatro anos após a aplicação de lodo de esgoto e cal cário. R. Bras. Ci. Solo, 15:237-240, 1991.

KAY, B.D. \& ANGERS, D.A. Soil structure. In: SUMNER, M.E., ed. Handbook of soil science. Washington, CRC Press, 1999. p. 229-276.

KEMPER, W.D. \& CHEPIL, W.S. Size distribution of aggregates. In: BLACK, C.A.; EVANS, D.D.; WHITE, J.L.; ENSMINGER, L.E. \& CLARK, F.E., eds. Methods of soil analysis - Physical and mineralogical properties, including statistics of measurement and sampling. Madison, American Society of Agronomy, 1965. p.499-510. (Agronomy Series, 9)

KOHNKE, H. Soil physics. New York, Mac Grow-Hill, 1968. p.118-142.

LEVY, G.J . \& TORRENTO, J.R. Clay dispersion and macroaggregate stability as affected by exchangeable potassium and sodium. Soil Sci., 160:352-358, 1995.

MARTIN, J.P.; MARTIN, W.P.; PAGE, J.B; RANEY, W.A. \& MENT, J .D. Soil aggregation. Adv. Agron., 7:1-37, 1955.

MBAGWU, J .S.C.; PICCOLO, A. \& MBILA, M.O. Water-stability of aggregates of some tropical soils treated with humic substances. Pedologie, 43:269-284, 1993.

MINITAB. Statistical Software. Release 13,1 (www. minitab.com). 2000.

MOLOPE, M.B.; GRIEVE, I.C. \& PAGE, E.R. Contributions by fungi and bacteria to aggregate stability of cultivated soils. J. Soil Sci., 38:71-77, 1987

OADES, J.M. Soil organic matter and structural stability: mechanisms and implications for management. Plant Soil, 76:319-337, 1984.

PALMEIRA, P.R.T.; PAULETO, E.A.; TEIXEIRA, C.F.A.; GOMES, A.S. \& SILVA, J B. Agregação de um Planossolo submetido a diferentes sistemas de cultivo. R. Bras. Ci. Solo, 23:189-195, 1999. 
RAIJ , B. van; ANDRADE, J .C.;. CANTARELLA H. \& QUAGGIO, J.A. Análise química para avaliação da fertilidade de solo tropicais. Campinas, Instituto Agronômico, 2001, 285p.

RAVINA, I. The mechanical and physical behavior of Ca-clay soil and K-clay soil. In: HADAS, A., ed. Physical aspects of soil water and salts in ecosystems. Berlin, Springer-Verlag, 1973. p. 131-140. (Ecological Studies, 4)

RENGASAMY, P., GREENE, R.S.B. \& FORD, G.W. Influence of magnesium on aggregate stability in sodic Red-Brown earths. Aust. J . Soil. Res, 24:229-237, 1986.

RENGASAMY, P. \& OLSSON, A. Sodicity and soil structure. Aust. J . Soil Res., 29:935-952, 1991.

RUSSEL, E.W. Soil conditions and plant growth. 10.ed. London: Longman, 1973.

SETZER, J . Atlas climático e ecológico do estado de São Paulo. São Paulo, Comissão Interestadual da Bacia ParanáUruguai,. CESP, 1966. 61p.

SHANMUGANATHAN, R.P. \& OADES, J .M. Modification of soil physical properties by manipulating the net surface charge on colloids through addition of Fe (III) polycations. J . Soil Sci., 33:451-465, 1982.
SILVA, I.F. \& MIELNICZUK, J . Ação do sistema radicular de plantas na formação e estabilização de agregados. R. Bras. Ci. Solo, 21:113-117, 1997.

TSCHAPEK, M. Química coloidal del suelo. I. Fenomenos de superficie. Buenos Aires, I mprenta y Casa Editora "Coni", 1949.

TISDALL, J .M.; COCKROFT, B. \& UREN, N.C. The stability of soil aggregates as affected by organic materials, microbial activity and physical disruption. Aust. J . Soil Res., 16:917, 1978.

TISDALL, J .M. \& OADES, L.M. Organic matter and water-stable aggregates in soil. J . Soil Sci., 33:141-163, 1982.

VANCE, E.D.; BROOKES, P.C. \& JENKINSON, D.S. An extraction method for measuring soil microbial biomass $C$. Soil Biol. Biochem., 19:703-707, 1987.

WISCHMEIER, W.H. \& SMITH, D.D. Predicting rainfall erosion losses - a guide to conservation planning. Washington, U.S. Department of Agriculture, 1978. 58p. (Agriculture Handbook, 537) 